\title{
Multi-Hazard System-Level Logit Fragility Functions
}

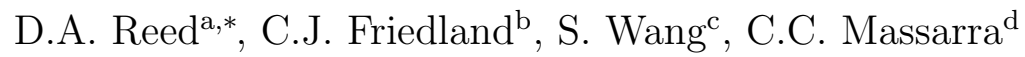

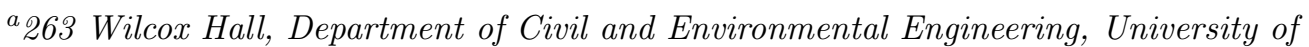 \\ Washington, Seattle, WA 98195 \\ ${ }^{b} 215$ Old Forestry Building, Department of Construction Management, Louisiana State \\ University, Baton Rouge, LA 70803 \\ ${ }^{c}$ Box 352650, Department of Industrial and Systems Engineering, University of \\ Washington, Seattle, WA 98195 \\ d216 Old Forestry Building, Department of Construction Management, Louisiana State \\ University, Baton Rouge, LA 70803
}

\begin{abstract}
Fragility functions are used to represent the probability of failure of a structure or lifeline system conditional upon a hazard or set of hazards and are essential in the performance-based design process. Continuous lognormal damage fragilities are traditional, but recent formulations have implemented logit transformations from the family of generalized linear models for categorical data with a binary outcome (e.g., failure, no failure). In wind engineering, single hazard parameters derived from correlated variables (e.g., integrated kinetic energy, IKE) have been employed to indirectly include the effect of more than one hazard variable; however, even with more general hazard metrics, the lognormal formulation is still unduly restrictive for realistic fragility modeling. Using a statistical approach based on a logit formulation, a shift towards more robust fragility functions can be achieved. Because

\footnotetext{
*Corresponding author

Email addresses: reed@uw.edu (D.A. Reed), friedland@lsu.edu (C.J. Friedland), shuoqw@uw.edu (S. Wang), cmassa1@lsu.edu (C.C. Massarra)
} 
of its simplicity and ability to represent multiple predictor variables to improve the fitted model, this paper proposes use of the logit formulation of the fragility function at the system level for two or more simultaneous weather hazards. Successful applications of the model to characterize lifeline systemlevel fragility functions for electric power delivery during Hurricane Isaac in Louisiana and Hurricane Sandy in New York City using in-situ damage and hazard data are shown. While the results here are empirically derived, the modeling approach may be expanded for other structural systems subject to multiple loadings or demand variables.

Keywords: Structural engineering, Wind engineering, Structural fragility, Hurricanes, Electric Power Delivery, Logistic regression

1. Introduction

Fragility functions are a cornerstone of the performance-based design pro3 cess in civil engineering. A fragility function is defined here as the probabil4 ity of failure of a structure or structural system conditional upon a hazard 5 or set of hazards. The estimation of building or bridge fragility for single 6 hazard parameters such as peak ground acceleration for seismic loadings or 7 3-second wind gusts for wind loadings, is considered mature, e.g.[1]. Whether given capacity, derived empirically or analytically, the representation is based upon a lognormal formulation as discussed in detail by Shinozuka et al. [1]. That is, the fragility function $F$ is modeled as a lognormal distribution with the two parameters $c$ and $\zeta$ as follows: 


$$
F(a)=\Phi\left[\frac{\ln \left(\frac{a}{c}\right)}{\zeta}\right]
$$

where $a$ represents the peak demand parameter; $\Phi(\cdot)$ is the standardized normal distribution function; $c$ and $\zeta$ are the two parameters of the lognormal distribution.

Many representations of structural fragilities of the form in equation (1) exist for different types of building constructions, e.g. $[2,3,4,5]$. One of the disadvantages of using the lognormal approach for modeling fragilities is the inability to capture the influence of more than one hazard simultaneously. Some investigators have tried to circumvent this problem by implementing hazard parameters that incorporate more than one variable. For example, for seismic fragilities, the Japanese Meteorological Agency (JMA) intensity scale or the instrumental Modified Mercalli Index $\left[I_{m m}\right]$ have been used [6]. The integrated kinetic energy [IKE] metric created by Powell and Reinhold [7] includes a combination of different aspects of the wind and storm surge potential, but it is challenging to use in predictions. For example, two IKE data points are presently available from HWind [8] on a daily basis for storms; however, the time scale is too long for use in estimating the level of structural damage required for fragility models. Due to the limitations of the lognormal approach described in equation (1), research in the use of logit transformations for seismic and wind hazards has been undertaken, e.g. [6, 9, 10, 11]. These research investigations were focused on individual hazards or damaged structures, such as bridges, and the use of empirical data was limited. In the next section, the modeling of fragilities through logit transformations is presented before application to post-event in-situ analysis for lifeline system is 
presented.

\section{Logit transformation and regression models for fragilities}

\subsection{Structural damage due to a single hazard}

The fragility function $F$ represents a conditional probability here in the general form of $E(\Im \mid H)$ where " $E$ " represents the expectation, "ऽ" is a binary event and " $H$ " is a hazard measure such as wind speed or peak ground acceleration. The logit transformation undertaken to evaluate $F=E(\Im \mid H)$ is as follows.

Define a binary event, $\Im$ as below:

$$
\Im= \begin{cases}1 & \text { system is damaged } \\ 0 & \text { system is not damaged }\end{cases}
$$

45 The probability distribution of $\Im$ is as follows:

$$
\Im= \begin{cases}1 & P(\Im=1)=\kappa(H) \\ 0 & P(\Im=0)=1-\kappa(H)\end{cases}
$$

where $P(*)=$ probability of $* ; \kappa(H)$ denotes a number on $[0,1]$. For a single hazard $H$, the logistic response function $F$ has the form, e.g. [13]:

$$
F=E(\Im \mid H)=P(\Im=1 \mid H)=\frac{\exp \left(\beta_{0}+\beta_{1} H\right)}{1+\exp \left(\beta_{0}+\beta_{1} H\right)}
$$

where $E(\cdot)=$ expected value; $\beta_{0}$ and $\beta_{1}$ are parameters of the logistic regression model.

The logit transformation of $F$ is given by 


$$
y(H)=\ln \left[\frac{\kappa(H)}{1-\kappa(H)}\right]=\beta_{0}+\beta_{1} H
$$

Equation (5) is for one hazard variable $H$ only. When using this format, typically, the parameter $\beta_{0}$ is referred to as the "intercept" and $\beta_{1}$ as the "coefficient". The ratio of $\kappa(H)$ to $(1-\kappa(H))$ is sometimes referred to as the "odds ratio". The advantage to using the logit model is that the function $F$ is transformed to a linear function $y$, which is easier to fit to actual data. It is noted that for the two parameter $F$, the $\beta_{0}$ parameter dictates the placement along the hazard variable axis, whereas the $\beta_{1}$ parameter controls the slope of the so-called "S" curve. Logistic transformation and regression models for fragilities have been used successfully in the earthquake community for evaluating fragilities of buildings, bridges and lifeline systems for single hazard metrics, e.g. [6, 11]. Lallemant et al. [12] note that lognormal and logit transformation models result in very similar curves but that logistic regression has the advantage of being easy to understand in that the estimated model coefficients represent the log of the odds ratio of damage due to a unit increase in the independent variable.

\subsection{Structural damage due to multiple hazards}

Distinct hazards generated simultaneously from a single event (e.g. hurricane) cause single and joint hazard damage and failure to structures and infrastructure. Modeling the effects of multiple hazards requires representation of hazard and hazard-structure interactions, as well as the cascading nature of hazard-induced damage $[14,15]$. The interaction of multiple hazards is widely believed to cause damage conditions that differ from the aggregation of single-hazard damage $[16,17]$. Therefore, statistical methods, which 
represent system-level response, are appropriate to represent infrastructure response to a range of multiple hazard conditions.

Equation (5) can be modified to include the influence of more than one hazard. Hazards may be considered separately as given in equation (6)

$$
\text { Linear model }: y=\beta_{0}+\beta_{1} H_{1}+\ldots+\beta_{m} H_{m}
$$

Here " $y$ " represents the dependent variable of fragility; $H_{i}$ represents the hazard variables; and $\beta_{i}$ are the fitted coefficients.

The linear model shown in equation (6) has been applied by Koutsourelakis [10] for geotechnical systems subject to earthquake hazards, where the hazard variables were the peak ground acceleration, and the root-meansquare intensity and the Arias intensity, which were calculated based upon the ground acceleration time history. The structure was modeled simplistically as located on a rigid foundation atop a deep sand deposit. It was concluded that including all three seismic hazard parameters provided a superior representation of the fragility function.

Gehl et al. [18] developed fragility functions with uncorrelated and correlated seismic intensity metrics for buildings. A simple unreinforced masonry structure was used in numerical simulations to provide examples of fragility functions. In each formulation, two intensity metrics were used for the two damage states of "yield" and "collapse" respectively. The use of two hazard parameters was found to be superior to a single-value hazard based fragility function.

In the companion papers $[19,20]$, fragility functions for aging highway bridge networks were modeled using both seismic loading variables and ma- 
terial deterioration effects as hazards. The material deterioration parameters were based on data derived from instrumented bridges and included surface chloride concentration, chloride diffusion coefficient and corrosion rate. The highway bridge network was modeled with bridges represented as nodes and roads represented as the connecting links. In [20], a fully parameterized fragility function with seven independent variables was derived. Only one of these variables was a seismic hazard intensity measure. Monte Carlo simulations were used to derive the fragilities employed for the bridges and highway networks.

Kameshwar and Padgett [19] derived fragility functions for bridges located in Charleston, South Carolina, subject to earthquake and hurricane hazards, respectively. Comparisons between earthquake and hurricane fragilities were made on the basis of numerical simulations. The models provided insight into the relative influence of each hazard parameter upon bridge risk.

Mardfekri and Gardoni [21] developed a probabilistic framework for the structural performance of offshore wind turbines subject to both wind and seismic loadings. The hazard data were modeled using extreme value seismic and wind load probability distributions at specific site locations. Annual probabilities of being in any specified damage state for the wind turbine at any particular location using the total probability rule were evaluated.

In all cases, fragilities were derived from numerical simulations. For network fragilities, the component fragilities of networks were determined and combined according to a network modeling approach. The ability of logistic models to characterize system response has been demonstrated, but the application of logistic models has been mostly for seismic hazards and the 
influence of material aging and deterioration of concrete bridges. Although correlations between seismic parameters were discussed by Koutsourelakis [10], interactions among the hazard variables were not directly modeled logistically; that is, products of hazard variables were not directly employed in the models.

Equation (7) provides the so-called interaction terms; it contains the linear model of equation (6) combined with a weighted sum of hazard product terms such as " $H_{j} H_{k}$ ":

Interaction model : $y=\beta_{0}+\beta_{1} H_{1}+\beta_{2} H_{2}+\ldots+\beta_{m} H_{m}+\sum_{1 \leq j \neq k \leq m}^{m} \beta_{j k} H_{j} H_{k}$

It is noted that the more hazard parameters considered, the more data are required for appropriate fitting; however, it is also anticipated that as data collections amass online each year, the data required for model fitting will be readily available in the near future. In the next section, interaction models will be presented for the hurricane hazards of storm surge, wind speed and rainfall using post-event in-situ hazard and damage data.

\section{Application to electric power lifeline systems for multiple weather hazards}

\subsection{Background on fragility models for electric power delivery lifelines}

Electric power is generated, transmitted and then fed through distribution network systems to buildings and other structural systems. Voltage drops occur at substations. Industrial or commercial facilities may have their own 
substations. Distribution lines may be located underground or overhead. For seismic loadings, substations are the most vulnerable structural components of the system [22]. For hurricanes, the towers and poles that comprise the lines feeding power to facilities are more vulnerable than the substations, especially in heavily wooded regions. If substations fail in hurricanes or other storms, it is due to flooding caused by excessive rainfall or storm surge, or through damaging wind-borne debris. Design guides and standards are available for the various structural components of the power grid, e.g. [23, $24,25,26]$. These guides may be implemented at a component level to assess the structural fragility as a "stand-alone" element of the network itself.

Seismic-based fragilities for the electric power delivery system have been investigated in greater detail than for wind-induced failures. In particular, the FEMA-based Multi-hazard Loss Estimation Methodology HAZUS-MH program [27] provides users with loss estimates based upon five possible structural damage states for generation facilities, substations and distribution circuits subject to seismic hazards. The hazards are characterized by peak ground acceleration. It is noted that HAZUS runs on ArcGIS software platforms, so geo-coding of the hazard data has been undertaken.

Park et al. [6] investigated the failure of an urban power delivery system through the use of the geographical information system [GIS] based power distribution grid overlaid with actual seismic intensities for the Nisqually earthquake of 2001. A thorough analysis of damage due to earthquake hazards in the region, yielded a lifeline fragility based upon the damage index, defined as the "length of a line damaged relative to the total length of a power line". It is noted that substation damage was not significant for the Nisqually 
earthquake. It was found that the damage index was equivalent to the total number of customer outages divided by the total number of customers at the neighborhood or county level. The importance of this result is that the number of outages is associated with the distribution system, which affects customers directly, and usually power companies supply these data for every earthquake or storm. In the US, the power grid is more vulnerable to storm events, whether these are winter storms or hurricanes, than earthquakes. Indeed, almost every hurricane season in the US produces remarkable outages in the Gulf of Mexico region. Recent Atlantic storms such as Sandy have wreaked havoc on the power grid in the northeastern US [28].

Formulations of the lifeline fragilities have been modified in recent years to characterize the loss of service through a fragility function, as opposed to a structural variable. In the case of electric power delivery, the "damage" variable of interest as used in this investigation was the inoperability $X(t)$, or inability to provide service. The maximum fraction of customers without power at time $t$, is denoted by $X_{\max }$, where $X_{\max }=\max \{X(t)$, for all $t\}$. In this section, the results of logit models described in equations (5), (6) and (7) fit to data collected for Hurricane Isaac and Sandy will be provided as a proof of concept in the approach. First, the data employed in the analysis are described and the limitations and caveats discussed. Then the model results are presented.

\subsection{Data used for the hurricane fragility analysis}

\subsubsection{Isaac}

Hurricane Isaac made first landfall at Southwest Pass in Louisiana on August 29, 2012 at 00:00 UTC with maximum sustained winds of $36 \mathrm{~m} / \mathrm{s}$ (70 
kt) [29]. According to Berg [29], the storm center moved back over water and then made second landfall west of Port Fourchon, Louisiana, later on August 29, 2012 at 08:00 UTC. The meteorological data of wind speed, inundation levels due to storm surge, and rainfall were cataloged for locations within the State of Louisiana. The description and sources of data are presented in Table 1.

There are limitations regarding the collected data. First, all of the hazards are uncertain random variables. Second, the geo-coded power grid was not available for overlay due to security reasons, so the damage data consisted of power delivery data per parish (county) obtained in spreadsheet format from the Louisiana Public Service Commission (LPSC) [30]. These data are not exact representations of damage, but close approximations, as noted previously. The LPSC provided outage time series data per parish as well as per utility or company at approximately half hour intervals from August 28 to September 7, 2012. The $X(t)$ function per parish, from which the peak $X_{\max }$ values were derived, has been studied in detail, e.g. [31, 32]. The $X_{\max }$ data were geo-coded and then overlaid with hazard data using ArcGIS software [33]. Figure 1 illustrates the ratio of peak customer outages to the total number of customers $X_{\max }$ per parish (county) in the State of Louisiana for Isaac. It can be seen that the percentages vary widely over the range of zero to one hundred. Figure 2 shows a map of the peak outages per parish. Although outage, wind speed and rainfall data were available for 64 parishes, only 20 were affected by storm surge. Therefore, the data set for the fragilities focused on the 20 parishes affected by all three hazards. 


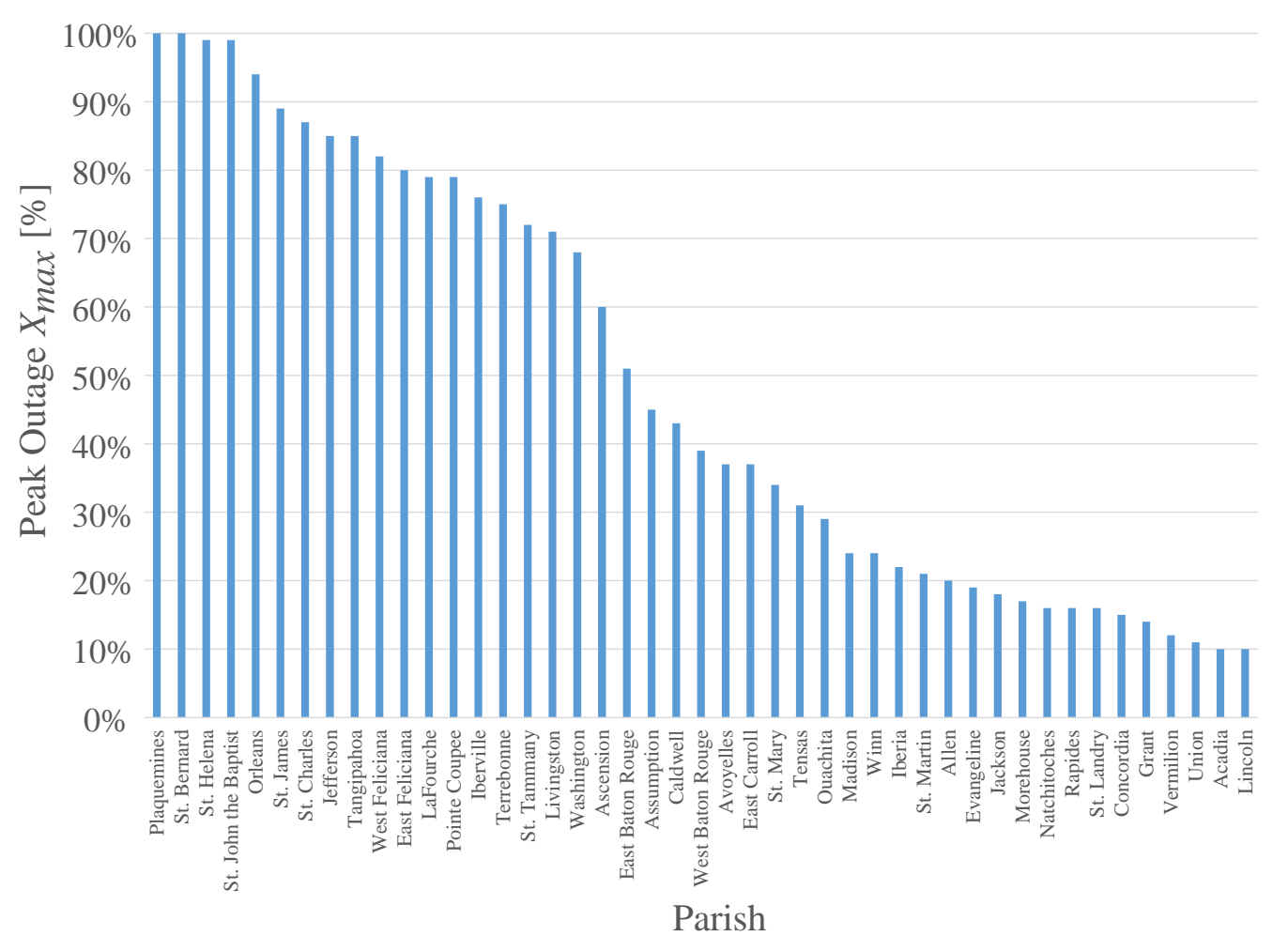

Figure 1: Peak outages $X_{\max }$ in percent per parish (county) in the State of Louisiana for Isaac (parishes with $X_{\max }$ less than $10 \%$ are not displayed)

\subsubsection{Sandy}

Hurricane Sandy made landfall near Brigantine, New Jersey, to the northeast of Atlantic City, on October 29, 2012 at approximately 23:30 UTC [34]. It was categorized as a post-tropical cyclone with an estimated intensity of $36 \mathrm{~m} / \mathrm{s}$ [70 kt] and a minimum pressure of $945 \mathrm{mb}$ [34]. The specifics of the hazard data are given in Table 2.

The limitations regarding the Isaac data also apply for Hurricane Sandy: all hazards are uncertain random variables and outage data were collected by Consolidated Edison (ConEd) employees and reported to the New York 


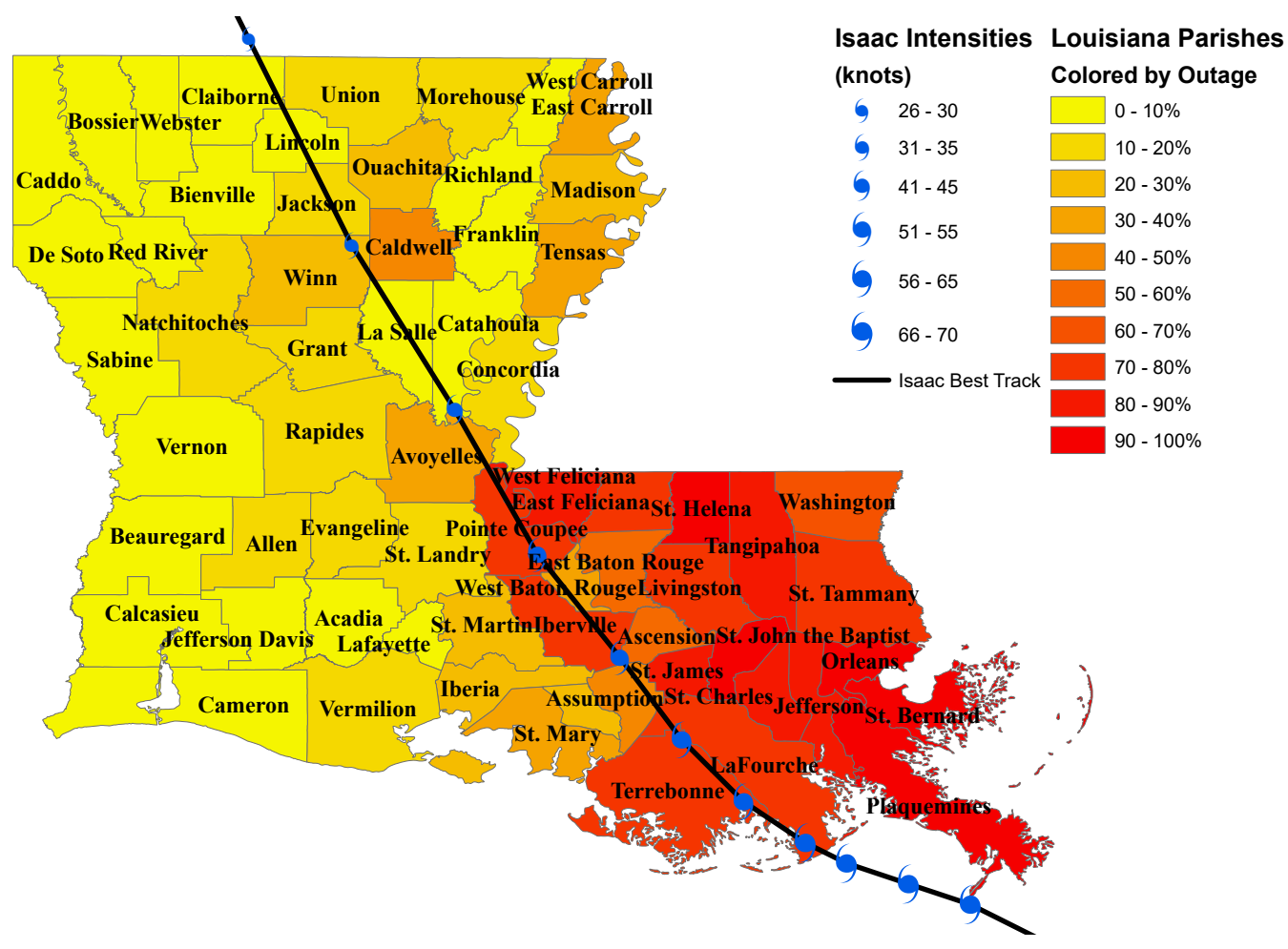

Figure 2: Map of peak power outages per parish in the State of Louisiana for Isaac overlaid with Hurricane Isaac Best Track

(Source: Parish boundary data provided by PennWell MAPSearch; Isaac Best Track and Intensities data provided by National Hurricane Center of National Oceanic and Atmospheric Administration (NOAA))

State Public Service Commission (NYSPSC). Specifically, NYSPSC provided electric power outage time series data per locality at approximately half hour intervals from October 29 to November 29, 2012 (some localities had longer or shorter periods) in spreadsheet format. The term "locality" is similar to "neighborhood" and its boundaries are defined by ConEd, who supplies electric power to Manhattan. It is noted that the spatial unit of "locality" is smaller than "parish" or "county" and the majority of the power lines 
in Manhattan are located underground. Figure 3 illustrates the ratio of peak customer outages to the total number of customers $X_{\max }$ per locality in Manhattan of the City of New York. The outage data were mostly zero or $100 \%$ for this data set. As with the Isaac data, the $X_{\max }$ data were geo-coded and then overlaid with hazard data using the ArcGIS software. Although outage data, rainfall and wind speed data were available for 32 localities in Manhattan, only 24 were affected by storm surge. Therefore, the data set for the fragilities focused on the 24 localities affected by all hazards. Figure 4 shows the localities of lower Manhattan that lost power during Hurricane Sandy. Also shown for reference is the location of ConEd's East 13th Street complex (including two transmission substations) near the intersection of East 13th Street and Avenue C.

\subsection{Model Analysis}

\subsubsection{Fitting methods}

Classical fitting techniques for logistic regression are based on an odds ratio [35]; that is, for this case, the variable $X_{\max }$ would only take on values of zero and unity, rather than the fractional values derived from the outage data. The model fitting investigation showed that the fractional values provided a superior fit to those for the binary $X_{\max }$ variable. The software environment $R$ [36] and 'arm' package [37] were used to fit the models.

The Maximum Likelihood Estimation (MLE) approach was used to estimate fragility model parameters by maximizing the likelihood function in equation (8), where $\Theta^{\mathrm{OPT}}$ are the optimal estimated parameters that maximize the likelihood function, $f(i)$ is the probability density function of variables with parameters $\theta$, and $\prod_{i=1}^{n} f\left(y_{i}, X_{i} ; \theta\right)$ is the likelihood function. The 


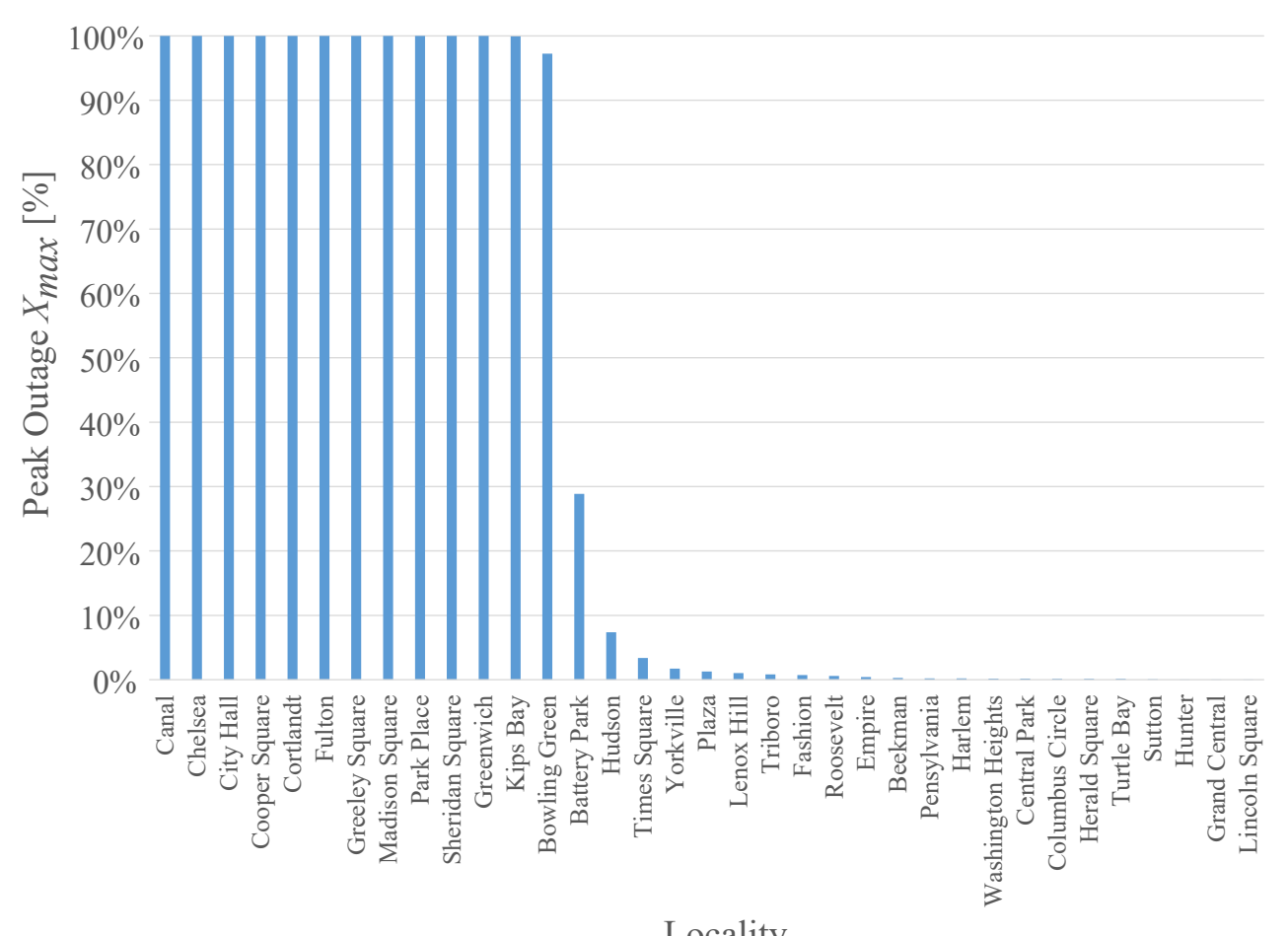

Figure 3: Peak outages $X_{\max }$ in percent per locality in Manhattan of the City of New York for Hurricane Sandy

257 Akaike Information Criterion (AIC) was used to select the best fitted model. 258 AIC provides an indication of the goodness of fit for the statistical model to the observed data. The AIC (equation (9)) adjusts the log-likelihood function (equation (10)) for the affected number of parameters $(K)$, where $\prod_{i=1}^{n} f\left(y_{i}, X_{i} ; \theta\right)$ is the likelihood function, and $f(i)$ is the probability density function of variables with parameters $\theta$.

$$
\Theta^{\mathrm{OPT}}=\arg \max \left[\prod_{i=1}^{n} f\left(y_{i}, X_{i} ; \theta\right)\right]
$$




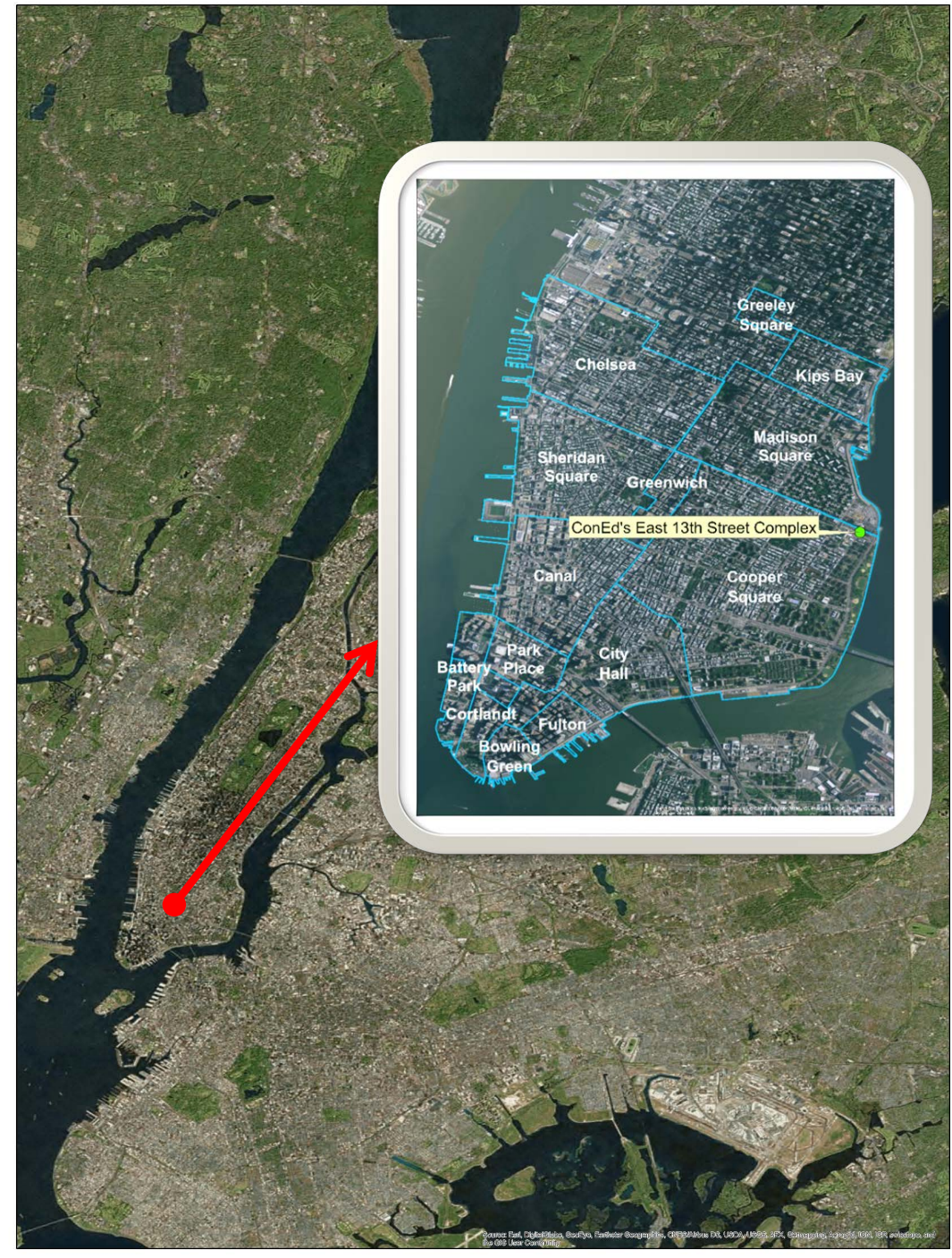

Figure 4: Locality map for lower Manhattan of the City of New York (Source of Imagery Basemap: Esri, DigitalGlobe, GeoEye, Earthstar Geographics, CNES/Airbus DS, USDA, USGS, AEX, Getmapping, Aerogrid, IGN, IGP, swisstopo, and the GIS User Community) 


$$
\begin{gathered}
\mathrm{AIC}=-2(\mathcal{L}(\theta \mid x))+2 K \\
\mathcal{L}(\theta \mid x)=\log \left(\prod_{i=1}^{n} f\left(y_{i}, X_{i} ; \theta\right)\right)
\end{gathered}
$$

The best fitted model of a group of models fit to the same data set should have the smallest AIC value. The symbol $\Delta_{i}$ is defined as "the difference of AIC value between the $i$ th model and the best fitted model" [38]. The strategy developed by Burnham and Anderson [38] was used to compare the goodness of fit of multiple models of a given sample set (Table 3). The larger the $\Delta_{i}$, the less plausible it is that the fitted model is the best model. As seen in Table 3, models with $\Delta_{i}>10$ are considered inappropriate.

\subsubsection{Results}

The logistic regression results for Hurricane Isaac using the peak outage $X_{\max }$ as a direct response variable are summarized in Table 4 for the sample size of $N=20$ data points as described in section 3.2.1.

Table 4 contains the fitted model parameters for the single hazard linear models, two hazard linear models, a three hazard linear model, two hazard models with interactions and finally, a three hazard model with multiple interactions. The significance of the fitted coefficients is provided through the p-values. The probability value (p-value) of a hypothesis test is the probability of obtaining a value of the test statistic as extreme, or more extreme, than the one observed, if the null hypothesis is true. The models are ranked in each category by the smallest to largest AIC values. Although the three hazard model with multiple interactions provides the overall lowest AIC value 
of 374.91, not all of the coefficients are significant. The two hazard linear model with rainfall and wind speed $(\mathrm{AIC}=398.40)$ is superior to models for either rainfall or wind speed alone ( $\mathrm{AIC}=428.49,462.68$, respectively). Figure 5 shows the 3-D surface for this particular model. The equation of the 3-D surface has the form as in equation (11):

$$
F\left(X_{\text {max }} \mid H_{1}, H_{2}\right)=\frac{\exp \left(-5.024+0.005 H_{1}+0.158 H_{2}\right)}{1+\exp \left(-5.024+0.005 H_{1}+0.158 H_{2}\right)}
$$

where $H_{1}$ and $H_{2}$ denote the rainfall [mm] and wind speed $[\mathrm{m} / \mathrm{s}]$ hazard variables respectively.

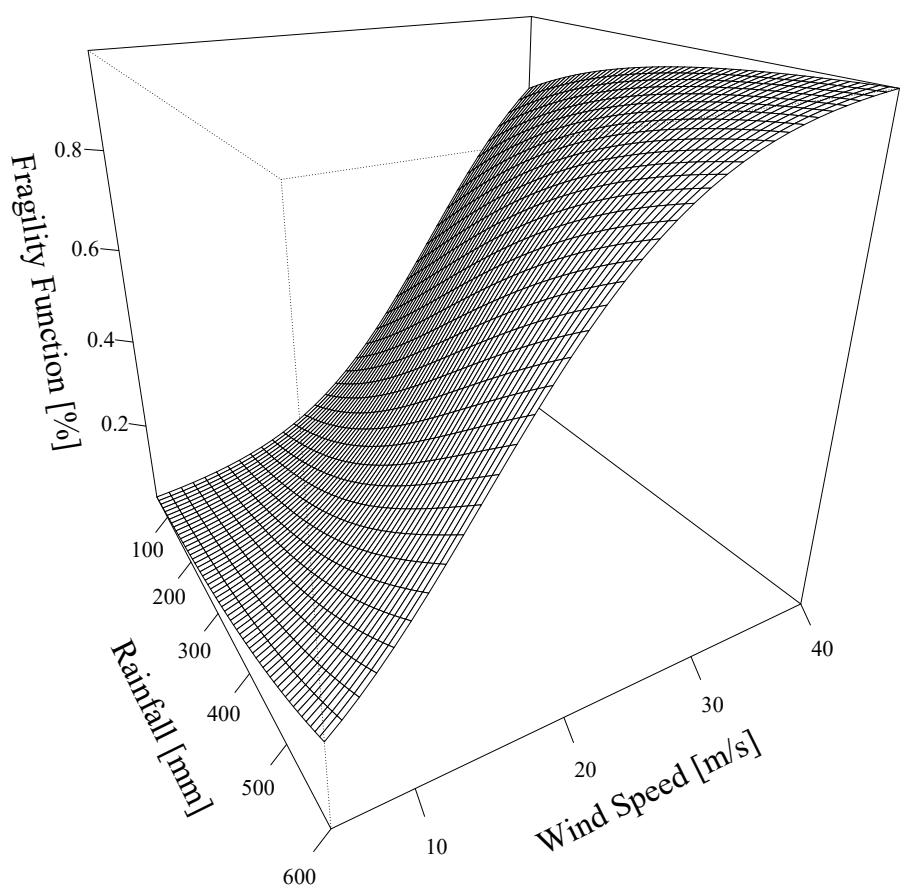

Figure 5: 3D surface for two hazard linear model with rainfall and wind speed for Isaac

Adding an interaction term to the two hazard linear model with rainfall 
and wind speed does not significantly decrease the AIC value (398.40 versus 398.54). The three hazard linear model with AIC of 400.71, which is close to 398.40, does not have a storm surge inundation coefficient value that is significant. In summary, the results suggest that the multiple hazard fragilities are better than the single hazard fragility representation, which confirms anecdotal observations regarding combined wind plus rain and surge damage, versus each alone. The lack of significance for the coefficients of the three hazard models with interactions may be due in part to the small data set.

In order to test the logistic model for an electric power delivery fragility in another region of the country, the Sandy data for the localities of Manhattan in the City of New York were used. As noted previously, the spatial resolution for this storm was much smaller than for Isaac. Because the majority of the power infrastructure was located underground, the three hazard model including wind speed was not a good fit.

The maximum storm surge and rainfall variables are reported here for Sandy, as shown in Table 5. The two hazard model results were superior to the single hazard models, which confirms the importance of multiple hazards on lifeline fragility. The interaction term did not appear to add much to the model fit and the coefficients were not as significant. In summary, the fragility based on combined storm surge inundation and rainfall hazards was the best model for Manhattan. Figure 6 illustrates this fragility model. The equation of the 3-D surface has the form as in equation (12):

$$
F\left(X_{\text {max }} \mid H_{1}, H_{3}\right)=\frac{\exp \left(-51.372+1.399 H_{1}+1.394 H_{3}\right)}{1+\exp \left(-51.372+1.399 H_{1}+1.394 H_{3}\right)}
$$

where $H_{1}$ and $H_{3}$ denote the rainfall [mm] and storm surge inundation [m] 
hazard variables respectively.

This result confirms observations that the bulk of the power grid in lower Manhattan is underground, with the exception of two power substations near the East River at East $13^{\text {th }}$ Street. Post event surveys showed that wind speed effects were significant in Westchester County where overhead lines were more prominent.

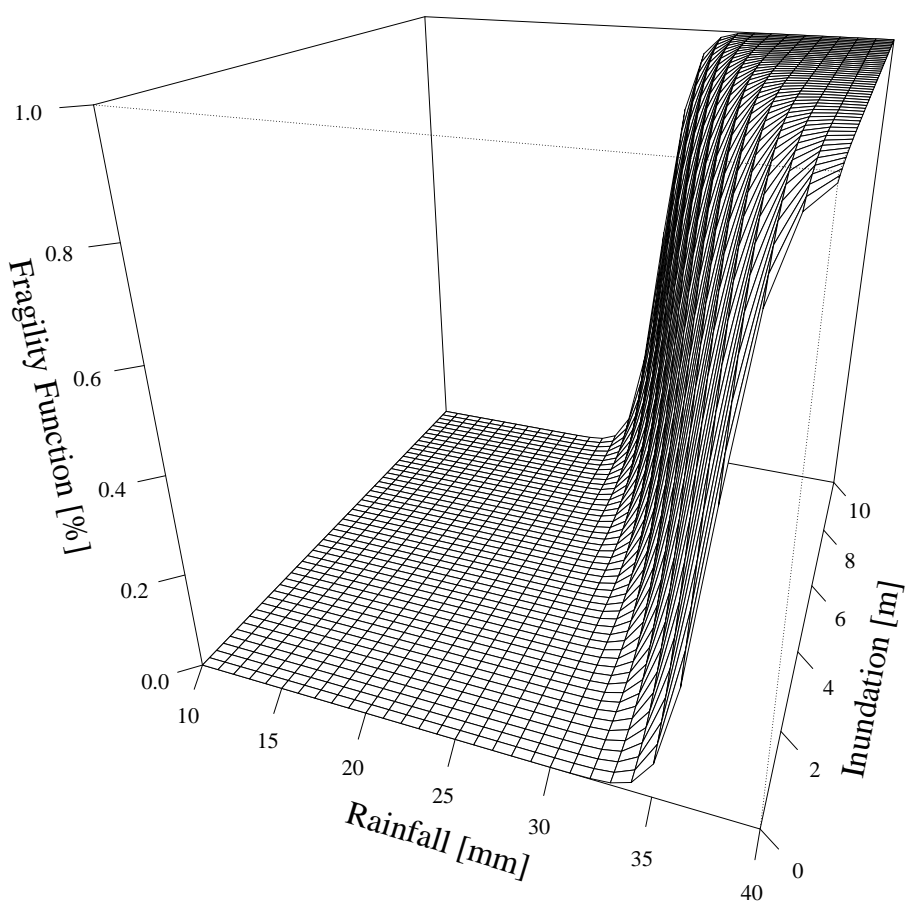

Figure 6: 3D surface for two hazard linear model with rainfall and storm surge for Sandy

\section{Discussion}

The characterization of lifeline fragilities using multiple hazards, including hazard interactions, as shown in section 3 , is an attractive alternative to 
lognormal single hazard models. The degree to which this additional characterization is useful may only be apparent after the damage due to multiple storms has been analyzed. However, the fragility function is only one facet of the performance-based design process $[4,5]$. Ultimately, in order to evaluate the performance of the delivery system for storm hazards, the multivariate probability density of the hazards is required. The theory of total probability indicates that an integration of the product of the conditional probability $F\left(X_{\max } \mid H=h\right)$ and marginal $f(h)$ or multivariate densities $f\left(h_{i}, h_{j}, \ldots\right)$ will yield a probability function. That is, the cumulative distribution function $F\left(X_{\max }\right)$ may be determined from the following integration if a multivariate model for $n$ hazards is used,

$$
F\left(X_{\max }\right)=\iiint_{h_{1}, \ldots, h_{n}} F\left(X_{\max } \mid h_{1}, \ldots, h_{n}\right) f\left(h_{1}, \ldots, h_{n}\right) d h_{1} \ldots d h_{n} .
$$

The representation of joint probability distributions for wind speed and storm surge data has been investigated recently, e.g. [39, 40, 41]. Pei et al. [39, 40] considered the joint occurrence of both hazards in a loss estimation scheme for Charleston County, South Carolina. They created a simulation approach that utilized over 50,000 years of synthetic hurricane data to model joint distributions numerically. Phan et al. [41] implemented a proof of concept investigation using bivariate Normal distributions. According to Johnson and Kotz [42] even if two variables are not Normal, their joint distribution may be Normal. However, one of the challenges in fitting the bivariate distribution of any type is the restriction of satisfying stability conditions for the functional form even if the marginal distributions do not completely specify the joint distribution, e.g.[42]. For a two hazard logit 
fragility model, the joint hazard distribution would be sufficient. For more complex three hazard fragilities, the multivariate hazard distribution would be required. For hurricane hazards, a form of a logistic hazard distribution $P_{H_{1} H_{2} H_{3}}$ is suggested as follows:

$$
P_{H_{1} H_{2} H_{3}}\left(h_{1}, h_{2}, h_{3}\right)=\frac{1}{1+e^{-\lambda_{1} h_{1}}+e^{-\lambda_{2} h_{2}}+e^{-\lambda_{3} h_{3}}+\sum_{i, j, i \neq j}^{3} e^{-\lambda_{i j} h_{i} h_{j}}}
$$

where $H_{1}, H_{2}$, and $H_{3}$ are defined as three random hazard variables; $\lambda_{1}, \lambda_{2}$, and $\lambda_{3}$ are coefficients.

It is noted that correlations among the hazard variables would need to be characterized for these distributions. However, a multivariate approach has yet to be fully explored for storm hazards. Whether the complexity of this model will provide the appropriate characterization remains to be seen.

In addition, the collection of data sets for modeling hazard and related damage will be essential. It is anticipated that predictive models of collected weather hazards will become available in the future from atmospheric scientists at the space and time scales necessary for engineering models.

\section{Summary and conclusions}

The methodology developed in this paper is useful to researchers, system owners, government agencies, insurance companies, and others who have access to large data sets describing system functionality during extreme events to facilitate generation of multi-hazard system-level fragility functions. The results of the case studies will be useful to practitioners evaluating system-level performance in Louisiana and New York. Most importantly, the methodology and results generated will be useful for multiple 
users who rely on loss functions for downstream analysis, including comparative risk assessment, overall system reliability and catastrophe models (e.g. used in the insurance industry).

In summary, logistic regression models have been used successfully to characterize fragilities for electric power delivery subject to hurricane hazards, where fragility is defined here as a conditional probability function. The system-level fragility models, while representing only single event scenarios, are based on geo-coded post-event in-situ hurricane weather hazard and power delivery system damage data rather than numerical simulations. Multiple simultaneous hazards of wind speed, rainfall and storm surge were used for the fragility model fits. This multi-hazard characterization property of the logit models is a distinct advantage over lognormal models. However, extensive GIS data are required for fitting the models. It is anticipated that continued investigations into the models presented here for other storms in the same geographical region will yield not only predictive capabilities, but also needed insight into the hurricane damage process. The characterization of the multivariate distributions of the simultaneous weather hazards will also improve damage predictions for hurricane prone regions.

\section{Acknowledgments}

This paper is based in part upon work supported by the National Science Foundation RAPID Collaborative for Hurricane Sandy under Grant Number CMMI 1316290 (Professor Dorothy Reed at the University of Washington) and CMMI 1316301 (Professor Carol Friedland at the Louisiana State University), as well as for Hurricane Isaac under Grant Number CMMI 
1263710 (Professor Dorothy Reed at the University of Washington) and CMMI 1263615 (Professor Carol Friedland at the Louisiana State University). Any opinions, findings, and conclusions or recommendations expressed in this paper are those of the author(s) and do not necessarily reflect the views of the National Science Foundation.

\section{References}

[1] M. Shinozuka, M. Q. Feng, J. Lee, T. Naganuma, Statistical analysis of fragility curves, Journal of Engineering Mechanics 126 (12) (2000) $1224-1231$.

[2] B. R. Ellingwood, D. V. Rosowsky, Y. Li, J. H. Kim, Fragility assessment of light-frame wood construction subjected to wind and earthquake hazards, Journal of Structural Engineering 130 (12) (2004) 1921-1930.

[3] J. W. van de Lindt, T. N. Dao, Performance-based wind engineering for wood-frame buildings, Journal of Structural Engineering 135 (2) (2009) $169-177$.

[4] F. Petrini, A probabilistic approach to performance-based wind engineering (PBWE), Ph.D. thesis, University of Rome, 2009.

[5] K. A. Porter, An overview of PEERs performance-based earthquake engineering methodology, in: Proceedings of Ninth International Conference on Applications of Statistics and Probability in Civil Engineering, 2003 . 
[6] J. Park, N. Nojima, D. A. Reed, Nisqually earthquake electric utility analysis, Earthquake spectra 22 (2) (2006) 491-509.

[7] M. D. Powell, T. A. Reinhold, Tropical cyclone destructive potential by integrated kinetic energy, Bulletin of the American Meteorological Society 88 (4) (2007) 513-526.

[8] HWind Scientific, Hwind Scientific Real-Time Hurricane Impact Data, online, URL http://www.hwind.co, 2015.

[9] J. Ghosh, K. Rokneddin, J. E. Padgett, L. Dueas-Osorio, Seismic Reliability Assessment of Aging Highway Bridge Networks with Field Instrumentation Data and Correlated Failures, I: Methodology, Earthquake Spectra 30 (2) (2014) 795-817, doi:10.1193/040512EQS155M, URL http://dx.doi.org/10.1193/040512EQS155M.

[10] P. Koutsourelakis, Assessing structural vulnerability against earthquakes using multi-dimensional fragility surfaces: a Bayesian framework, Probabilistic Engineering Mechanics 25 (1) (2010) 49-60.

[11] N. Nojima, M. Sugito, Probabilistic assessment model for postearthquake serviceability of utility lifelines and its practical application, in: G. Augusti, G. Schuller, M. Ciampoli (Eds.), Safety and Reliability of Engineering Systems and Structures (Proc. of the 9th International Conference on Structural Safety and Reliability (ICOSSAR 2005)), Millpress, 2006.

[12] D. Lallemant, A. Kiremidjian, H. Burton, Statistical procedures for de- 
veloping earthquake damage fragility curves, Earthquake Engineering \& Structural Dynamics 44 (9) (2015) 1373-1389.

[13] D. W. Hosmer Jr, S. Lemeshow, Applied logistic regression, New York: Wiley, 2000.

[14] W. Marzocchi, A. Garcia-Aristizabal, P. Gasparini, M. L. Mastellone, A. Di Ruocco, Basic principles of multi-risk assessment: a case study in Italy, Natural hazards 62 (2) (2012) 551-573.

[15] M. C. McCullough, A. Kareem, A. S. Donahue, J. J. Westerink, Structural damage under multiple hazards in coastal environments, Journal of Disaster Research 8 (2013) 1042-1051.

[16] M. Kappes, M. Papathoma-Köhle, M. Keiler, Assessing physical vulnerability for multi-hazards using an indicator-based methodology, Applied Geography 32 (2) (2012) 577-590.

[17] M. S. Kappes, M. Keiler, K. von Elverfeldt, T. Glade, Challenges of analyzing multi-hazard risk: a review, Natural Hazards 64 (2) (2012) $1925-1958$.

[18] P. Gehl, D. M. Seyedi, J. Douglas, Vector-valued fragility functions for seismic risk evaluation, Bulletin of Earthquake Engineering 11 (2) (2013) $365-384$.

[19] S. Kameshwar, J. E. Padgett, Multi-hazard risk assessment of highway bridges subjected to earthquake and hurricane hazards, Engineering Structures 78 (2014) 154-166. 
[20] K. Rokneddin, J. Ghosh, L. Dueñas-Osorio, J. E. Padgett, Seismic Reliability Assessment of Aging Highway Bridge Networks with Field Instrumentation Data and Correlated Failures, II: Application, Earthquake Spectra 30 (2) (2014) 819-843.

[21] M. Mardfekri, P. Gardoni, Multi-hazard reliability assessment of offshore wind turbines, Wind Energy 18 (8) (2015) 1433-1450, ISSN 1099-1824, doi:10.1002/we.1768, URL http://dx.doi.org/10.1002/we.1768.

[22] H. J. Dagher, Reliability-Based Design Committee of the Structural Engineering Institute, Reliability-based Design of Utility Pole Structures (ASCE manuals and reports on engineering practice No. 111), American Society of Civil Engineers, Reston, VA, 2006.

[23] M. D. Miller, C. J. Wong, Task Committee on Structural Loadings of the American Society of Civil Engineers, Guidelines for electrical transmission line structural loading (ASCE manuals and reports on engineering practice No. 74), American Society of Civil Engineer, Reston, Va., 2010.

[24] W. J. Oliphant, D. C. Sherman, Task Committee on Concrete Pole Structures of the Structural Engineering Institute, Prestressed concrete transmission pole structures : recommended practice for design and installation (ASCE manuals and reports on engineering practice No. 123), American Society of Civil Engineers, Reston, Va., 2012.

[25] Subcommittee on Fiber-Reinforced Composite Structures for Overhead Lines of the American Society of Civil Engineers, Recommended practice for fiber-reinforced polymer products for overhead utility line structures 
(ASCE manuals and reports on engineering practice No. 104), American Society of Civil Engineers, Reston, Va., 2003.

[26] Subcommittee on Guyed Transmission Structures of the American Society of Civil Engineers, Design of guyed electrical transmission structures (ASCE manuals and reports on engineering practice No. 91), American Society of Civil Engineers, New York, N.Y., 1997.

[27] Federal

Emergency

Management

Agency

(FEMA), HAZUS-MH Earthquake Model, URL http: //www.fema.gov/hazus-mh-earthquake-model, 2015.

[28] The Special Initiative for Rebuilding and Resiliency (SIRR), A Stronger, More Resilient New York, The City of New York, New York, NY, 2013.

[29] R. Berg, Tropical Cyclone Report Hurricane Isaac (AL092012) 21 August1 September 2012., Tech. Rep., National Hurricane Center of National Oceanic and Atmospheric Administration/National Weather Service, 2013.

[30] Louisiana Public Service Commission (LPSC), Emergency operations center: daily service outage report (Excel spreadsheets for each day summarizing electric and phone outage), 2012.

[31] D. A. Reed, M. D. Powell, J. M. Westerman, Energy infrastructure damage analysis for Hurricane Rita, Natural Hazards Review 11 (3) (2010) 102-109. 
[32] D. Reed, K. C. Kapur, R. D. Christie, Methodology for assessing the resilience of networked infrastructure, Systems Journal, IEEE 3 (2) (2009) $174-180$.

[33] ESRI, ArcGIS, the mapping platform, URL http://www.arcgis.com, 2015.

[34] E. S. Blake, T. B. Kimberlain, R. J. Berg, J. Cangialosi, J. L. Beven II, Tropical cyclone report: Hurricane Sandy TCR-AL182012, Tech. Rep., National Hurricane Center, 2013.

[35] D. C. Montgomery, G. C. Runger, Applied statistics and probability for engineers, Wiley, Hoboken, NJ, 5th ed. edn., 2011.

[36] R Core Team, R: A Language and Environment for Statistical Computing, R Foundation for Statistical Computing, Vienna, Austria, URL https://www.R-project.org, 2015.

[37] A. Gelman, Y.-S. Su, M. Yajima, J. Hill, M. G. Pittau, J. Kerman, T. Zheng, V. Dorie, Data Analysis Using Regression and Multilevel/Hierarchical Models. R package version 1.8-6, URL https://cran.r-project.org/web/packages/arm/index.html, 2015.

[38] K. P. Burnham, D. R. Anderson, Model selection and multimodel inference: a practical information-theoretic approach, Springer Science \& Business Media, 2002.

[39] B. Pei, W. Pang, F. Testik, N. Ravichandran, Joint Distributions of Hurricane Wind and Storm Surge for the City 
of Charleston in South Carolina, American Society of Civil Engineers, 703-714, doi:10.1061/9780784412626.062, URL http://ascelibrary.org/doi/abs/10.1061/9780784412626.062, 2013.

[40] B. Pei, W. Pang, F. Y. Testik, N. Ravichandran, F. Liu, Mapping joint hurricane wind and surge hazards for Charleston, South Carolina, Natural Hazards 74 (2) (2014) 375-403.

[41] L. Phan, E. Simiu, M. McInerney, A. Taylor, B. Glahn, M. Powell, NIST Technical Note 1482, Methodology for development of design criteria for joint hurricane wind speed and storm surge events: Proof of concept, Department of Commerce, U.S. Government, Gaithersburg, M.D., 2007.

[42] N. L. Johnson, S. Kotz, Continuous multivariate distributions, New York, Wiley, 1972.

[43] The Coastal Emergency Risks Assessment (CERA) Group, CERA - Coastal Emergency Risks Assessment, online, URL http://cera.cct.1su.edu, 2015.

[44] National Weather Service, Advanced Hydrologic Prediction Service, online, URL http://water.weather.gov/precip/download.php, 2015.

[45] FEMA Modeling Task Force (MOTF), FEMA MOTF Hurricane Sandy Impact Analysis, online, URL http: //www . arcgis. com/home/item . html?id=307dd522499d4a44a33d7296a5da5ea0, 2015 . 
Table 1: Hazard Data Employed in the Isaac Analysis

\begin{tabular}{|c|c|c|}
\hline Data & Description & Source \\
\hline $\begin{array}{l}\text { Wind Speed } \\
{[\mathrm{m} / \mathrm{s}]}\end{array}$ & $\begin{array}{l}\mathrm{H}^{*} \text { Wind: Maximum sus- } \\
\text { tained wind speed swaths } \\
\text { for Hurricane Isaac for the } \\
\text { State of Louisiana. }\end{array}$ & HWind Scientific $^{\dagger}[8]$ \\
\hline $\begin{array}{l}\text { Inundation } \\
\text { due to } \\
\text { Storm Surge } \\
{[\mathrm{m}]}\end{array}$ & $\begin{array}{l}\text { Depth of water above lo- } \\
\text { cal land elevation as deter- } \\
\text { mined for storm surge using } \\
\text { hindcasting. }\end{array}$ & $\begin{array}{l}\text { Coastal Emergency Risks } \\
\text { Assessment (CERA) [43] }\end{array}$ \\
\hline $\begin{array}{l}\text { Rainfall } \\
{[\mathrm{mm}]}\end{array}$ & $\begin{array}{l}\text { Observed daily precipita- } \\
\text { tion for the duration of the } \\
\text { storm. }\end{array}$ & $\begin{array}{l}\text { National Weather Service, } \\
\text { Advanced Hydrologic Pre- } \\
\text { dictive Service }[44]\end{array}$ \\
\hline \multicolumn{3}{|c|}{$\begin{array}{l}\text { † Note: The Hurricane Research Division of the National Oceanic \& } \\
\text { Atmospheric Administration produced surface wind analysis of tropi- } \\
\text { cal cyclones from } 1993 \text { - } 2013 \text { as part of the } \mathrm{H}^{*} \text { Wind Project. In } 2014 \\
\text { this activity was transferred to HWind Scientific, a US private sector } \\
\text { firm. The images and data sets formerly available on the Hurricane } \\
\text { Research Division website are now publicly available on the HWind } \\
\text { Scientific website. }\end{array}$} \\
\hline
\end{tabular}


Table 2: Hazard Data Employed in the Sandy Analysis

\begin{tabular}{|c|c|c|}
\hline Data & Description & Source \\
\hline $\begin{array}{l}\text { Wind Speed } \\
{[\mathrm{m} / \mathrm{s}]}\end{array}$ & $\begin{array}{l}\mathrm{H}^{*} \text { Wind: Maximum sus- } \\
\text { tained wind speed swaths } \\
\text { for Hurricane Sandy for the } \\
\text { New York City. }\end{array}$ & HWind Scientific $^{\dagger}[8]$ \\
\hline $\begin{array}{l}\text { Storm Surge } \\
\text { Inundation } \\
{[\mathrm{m}]}\end{array}$ & $\begin{array}{l}\text { Water surface elevation } \\
\text { above local ground inter- } \\
\text { polated using High Water } \\
\text { Marks (HWMs) and Storm } \\
\text { Surge Sensor data from the } \\
\text { United States Geological } \\
\text { Survey (USGS) }\end{array}$ & $\begin{array}{l}\text { Federal Emergency } \text { Man- } \\
\text { agement Agency (FEMA) } \\
\text { Modeling Task } \text { Force } \\
\text { (MOTF) [45] }\end{array}$ \\
\hline $\begin{array}{l}\text { Rainfall } \\
{[\mathrm{mm}]}\end{array}$ & $\begin{array}{l}\text { Observed daily precipita- } \\
\text { tion for the duration of the } \\
\text { storm. }\end{array}$ & $\begin{array}{l}\text { National Weather Service, } \\
\text { Advanced Hydrologic Pre- } \\
\text { dictive Service }[44]\end{array}$ \\
\hline \multicolumn{3}{|c|}{$\begin{array}{l}\dagger \text { Note: The Hurricane Research Division of the National Oceanic \& } \\
\text { Atmospheric Administration produced surface wind analysis of tropi- } \\
\text { cal cyclones from } 1993 \text { - } 2013 \text { as part of the } H^{*} \text { Wind Project. In } 2014 \\
\text { this activity was transferred to HWind Scientific, a US private sector } \\
\text { firm. The images and data sets formerly available on the Hurricane } \\
\text { Research Division website are now publicly available on the HWind } \\
\text { Scientific website. }\end{array}$} \\
\hline
\end{tabular}


Table 3: Interpretation of AIC difference $\Delta_{i}$ [38]

\begin{tabular}{|c|l|}
\hline$\Delta_{i}$ & Level of Empirical Support of Model $i$ \\
\hline $0 \sim 2$ & Substantial \\
\hline $4 \sim 7$ & Considerably less \\
\hline$>10$ & Essentially none \\
\hline
\end{tabular}


Table 4: Hurricane Isaac Fragility Fit Results

\begin{tabular}{|c|c|c|c|c|c|}
\hline \multicolumn{6}{|c|}{$\ddagger$ Significance code for the p-value Column: between $0 \sim 0.01^{* * *} ; 0.01 \sim 0.05^{* *} ; 0.05 \sim 0.1^{*}$} \\
\hline Model Variables & Coefficients & Estimate & $\begin{array}{c}\text { Standard } \\
\text { Error }\end{array}$ & ${ }^{\ddagger}$ p-value & $\mathrm{AIC}$ \\
\hline \multicolumn{6}{|c|}{ Single Hazard Linear Model Results listed in order of lowest AIC } \\
\hline \multirow{2}{*}{$X_{\max } \sim$ Wind $[\mathrm{m} / \mathrm{s}]$} & Intercept $\beta_{0}$ & -5.748 & 0.267 & $<2 \mathrm{e}-16^{* * *}$ & \multirow{2}{*}{428.49} \\
\hline & Wind $[\mathrm{m} / \mathrm{s}]$ & 0.248 & 0.011 & $<2 \mathrm{e}-16^{* * *}$ & \\
\hline \multirow{2}{*}{$X_{\max } \sim$ Rainfall $[\mathrm{mm}]$} & Intercept $\beta_{0}$ & -3.206 & 0.159 & $<2 \mathrm{e}-16^{* * *}$ & \multirow{2}{*}{462.68} \\
\hline & Rainfall $[\mathrm{mm}]$ & 0.011 & 0.0004 & $<2 \mathrm{e}-16^{* * *}$ & \\
\hline \multirow{2}{*}{$X_{\max } \sim$ Inundation $[\mathrm{m}]$} & Intercept $\beta_{0}$ & -2.165 & 0.121 & $<2 \mathrm{e}-16^{* * *}$ & \multirow{2}{*}{477.38} \\
\hline & Inundation $[\mathrm{m}]$ & 1.119 & 0.049 & $<2 \mathrm{e}-16^{* * *}$ & \\
\hline \multicolumn{6}{|c|}{ Two Hazard Linear Model Results listed in order of lowest AIC } \\
\hline \multirow{3}{*}{$X_{\max } \sim$ Rainfall $[\mathrm{mm}]+$ Wind $[\mathrm{m} / \mathrm{s}]$} & Intercept $\beta_{0}$ & -5.024 & 0.291 & $<2 \mathrm{e}-16^{* * *}$ & \multirow{3}{*}{398.40} \\
\hline & Rainfall [mm] & 0.005 & 0.001 & $1.69 \mathrm{e}-07^{* * *}$ & \\
\hline & Wind $[\mathrm{m} / \mathrm{s}]$ & 0.158 & 0.019 & $3.31 \mathrm{e}-16^{* * *}$ & \\
\hline \multirow[b]{2}{*}{$X_{\max } \sim$ Inundation $[\mathrm{m}]+$ Wind $[\mathrm{m} / \mathrm{s}]$} & Intercept $\beta_{0}$ & -4.681 & 0.356 & $<2 \mathrm{e}-16^{* * *}$ & \multirow[b]{2}{*}{413.06} \\
\hline & Inundation $[\mathrm{m}]$ & 0.399 & 0.096 & $3.07 \mathrm{e}-15^{* * *}$ & \\
\hline
\end{tabular}




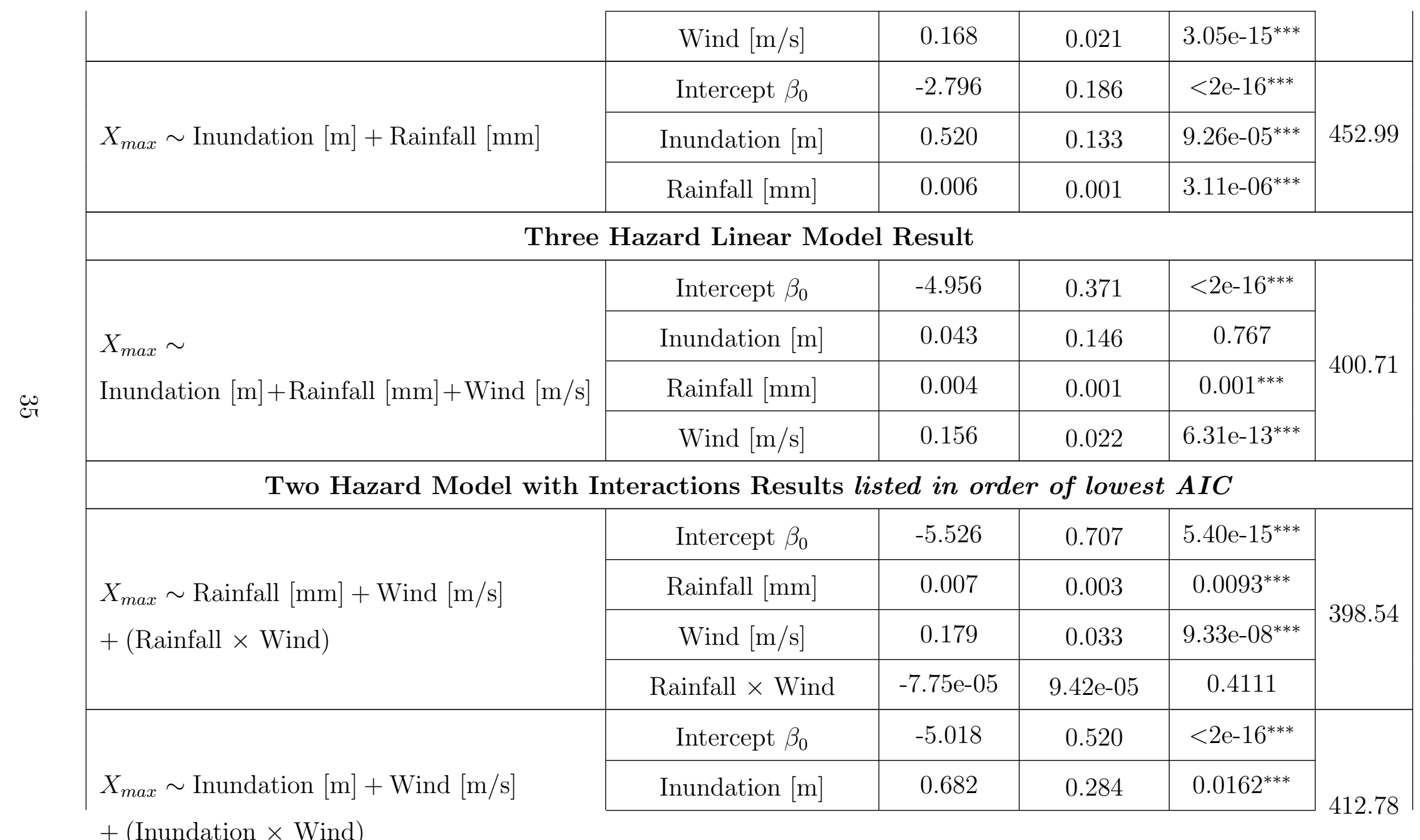




\begin{tabular}{|c|c|c|c|c|c|}
\hline & Wind $[\mathrm{m} / \mathrm{s}]$ & 0.179 & 0.026 & $2.38 \mathrm{e}-12^{* * *}$ & \\
\hline & Inundation $\times$ Wind & -0.009 & 0.009 & 0.310 & \\
\hline \multirow{4}{*}{$\begin{array}{l}X_{\max } \sim \text { Inundation }[\mathrm{m}]+\text { Rainfall }[\mathrm{mm}] \\
+(\text { Inundation } \times \text { Rainfall })\end{array}$} & Intercept $\beta_{0}$ & -3.359 & 0.296 & $<2 \mathrm{e}-16^{* * *}$ & \multirow{4}{*}{447.82} \\
\hline & Inundation [m] & 0.976 & 0.216 & $6.33 \mathrm{e}-06^{* * *}$ & \\
\hline & Rainfall [mm] & 0.008 & 0.001 & $2.04 \mathrm{e}-07^{* * *}$ & \\
\hline & Inundation $\times$ Rainfall & -0.001 & 0.000 & $0.00926^{* * *}$ & \\
\hline \multicolumn{6}{|c|}{ Three Hazard Model with Multiple Interactions Result } \\
\hline \multirow{8}{*}{$\begin{array}{l}X_{\max } \sim \text { Inundation }[\mathrm{m}]+\text { Rainfall }[\mathrm{mm}] \\
+ \text { Wind }[\mathrm{m} / \mathrm{s}]+(\text { Inundation } \times \text { Rainfall })+ \\
(\text { Inundation } \times \text { Wind })+(\text { Rainfall } \times \text { Wind })+ \\
(\text { Inundation } \times \text { Rainfall } \times \text { Wind })\end{array}$} & Intercept $\beta_{0}$ & -11.140 & 1.430 & $6.84 \mathrm{e}-15^{* * *}$ & \multirow{8}{*}{374.91} \\
\hline & Inundation $[\mathrm{m}]$ & 0.040 & 0.423 & 0.925 & \\
\hline & Rainfall $[\mathrm{mm}]$ & 0.042 & 0.009 & $2.55 \mathrm{e}-06^{* * *}$ & \\
\hline & Wind $[\mathrm{m} / \mathrm{s}]$ & 0.413 & 0.065 & $2.32 \mathrm{e}-10^{* * *}$ & \\
\hline & Inundation $\times$ Rainfall & -0.006 & 0.002 & $0.0061^{* * *}$ & \\
\hline & Inundation $\times$ Wind & -0.004 & 0.014 & 0.7942 & \\
\hline & Rainfall $\times$ Wind & -0.001 & $3.16 \mathrm{e}-04$ & $3.85 \mathrm{e}-06^{* * *}$ & \\
\hline & $\begin{array}{l}\text { Inundation } \times \text { Rainfall } \\
\times \text { Wind }\end{array}$ & $2.44 \mathrm{e}-04$ & $6.81 \mathrm{e}-05$ & $0.0003^{* * *}$ & \\
\hline
\end{tabular}


Table 5: Hurricane Sandy Fragility Fit Results for Manhattan Localities Only

\begin{tabular}{|c|c|c|c|c|c|}
\hline \multicolumn{6}{|c|}{$\ddagger$ Significance code for the p-value Column: between $0 \sim 0.01^{* * *} ; 0.01 \sim 0.05^{* *} ; 0.05 \sim 0.1^{*}$} \\
\hline Model Variables & Coefficients & Estimate & Standard Error & ${ }^{\ddagger}$ p-value & $\mathrm{AIC}$ \\
\hline \multicolumn{6}{|c|}{ Single Hazard Linear Model Results listed in order of lowest AIC } \\
\hline \multirow{2}{*}{$X_{\max } \sim$ Rainfall $[\mathrm{mm}]$} & Intercept $\beta_{0}$ & -45.346 & 2.504 & $<2 \mathrm{e}-16^{* * *}$ & \multirow{2}{*}{1693.30} \\
\hline & Rainfall $[\mathrm{mm}]$ & 1.410 & 0.0770 & $<2 \mathrm{e}-16^{* * *}$ & \\
\hline \multirow{2}{*}{$X_{\max } \sim$ Inundation $[\mathrm{m}]$} & Intercept $\beta_{0}$ & -8.770 & 0.417 & $<2 \mathrm{e}-16^{* * *}$ & \multirow{2}{*}{2438.40} \\
\hline & Inundation $[\mathrm{m}]$ & 1.880 & 0.088 & $<2 \mathrm{e}-16^{* * *}$ & \\
\hline \multicolumn{6}{|c|}{ Two Hazard Linear Model Results: With and Without Interaction } \\
\hline \multirow{3}{*}{$\begin{array}{l}X_{\max } \sim \text { Inundation }[\mathrm{m}] \\
+ \text { Rainfall }[\mathrm{mm}]\end{array}$} & Intercept $\beta_{0}$ & -51.372 & 2.667 & $<2 \mathrm{e}-16^{* * *}$ & \multirow{3}{*}{1353.10} \\
\hline & Inundation $[\mathrm{m}]$ & 1.394 & 0.096 & $<2 \mathrm{e}-16^{* * *}$ & \\
\hline & Rainfall $[\mathrm{mm}]$ & 1.399 & 0.079 & $<2 \mathrm{e}-16^{* * *}$ & \\
\hline \multirow{4}{*}{$\begin{array}{l}X_{\max } \sim \text { Inundation }[\mathrm{m}] \\
+ \text { Rainfall }[\mathrm{mm}] \\
+ \text { Inundation } \times \text { Rainfall }\end{array}$} & Intercept $\beta_{0}$ & -42.982 & 7.244 & $<2.96 \mathrm{e}-09^{* * *}$ & \multirow{4}{*}{1357.30} \\
\hline & Inundation $[\mathrm{m}]$ & -0.251 & 1.378 & 0.855 & \\
\hline & Rainfall $[\mathrm{mm}]$ & 1.138 & 0.224 & $3.84 \mathrm{e}-07^{* * *}$ & \\
\hline & Inundation $\times$ Rainfall & 0.051 & 0.043 & 0.232 & \\
\hline
\end{tabular}

